\title{
ESTUDIO DEL CASO : EL PLAN MAESTRO DEL TRANSPORTE URBANO PARA EL ÁREA DE LIMA METROPOLITANA - CALLAO EN LA REPÚBLICA DEL PERÚ ${ }^{1}$
}

\author{
Néstor Adolfo Mamani Macedo ${ }^{2}$
}

\begin{abstract}
Resumen.- El área de Lima metropolitana - Callao está localizada en el centro del Perú, frente al Océano Pacífico. Lima es la capital y funciona como centro político y administrativo del país. Callao es el principal puerto marítimo del Perú y es uno de los más importantes de América del Sur. Tanto el municipio de Lima como el del Callao tienen autonomía y-de acuerdo a ley tienen las mismas atribuciones. En este sentido, cualquier solución al problema de transporte en Lima está necesariamente vinculada a una solución del transporte en el Callao. En realidad, desde una óptica social, económica y cultural las dos cuidades constituyen una unidad.

Es evidente, por tanto, la importancia de desarrollar un Plan Maestro del Transporte en el área de Lima metropolitana - Callao. El Plan Maestro desarrollado por Yachiyo Engineering Co. Ltd. tiene planos específicos para los siguientes sectores: Red Vial, Ferroviaria, Omnibús troncales, y Gestión de Tránsito, identificándose para cada uno de estos, proyectos relevantes para el transporte en el año 2025 y 2010.
\end{abstract}

Palabras claves: Red vial, transporte público, gas natural, contaminación ambiental.

\footnotetext{
${ }^{1}$ Apresentado no I Curso Internacional Praticas de Gestão Urbana realizado entre o 23-02-2007 e o 2503-2007, pelo Instituto de Pesquisa e Planejamento Urbano de Curitiba (IPPUC) Brasil sob o auspicio da Agencia Brasileira de Cooperação (ABC) e da Japan International Cooperation Agency (JICA Japão). Artigo baseado no Estudo de Consultoria Plan Maestro de Transporte Urbano para el Área Metropolitana de Lima y Callao en la República del Perú. (Espanhol) da Yachiyo Engineering Co. Ltd. em associação com Pacific Consultants Internacional. Agosto, 2005.

${ }^{2}$ Grupo de Pesquisa em Pólos Geradores de Viagens Instituto de Investigación Facultad de Ciencias Matemáticas Universidad Nacional Mayor de San Marcos - e-mail:nmamani@unmsm.edu.pe Instituto de Ingeniería de Transportes PACIS IberoAmérica - e-mail:nestor@pacisnet.org Membro da Rede Iberoamericana de Polos Geradores de Viagens.
} 


\title{
THE STUDY OF THE CASE : THE MASTER PLAN OF URBAN TRANSPORT FOR THE AREA OF METROPOLITAN LIMA - CALLAO IN THE REPUBLIC OF PERU
}

\begin{abstract}
The metropolitan area of Lima - Callao is located in the center of Peru, facing the Pacific Ocean. Lima is the capital and serves as political and administrative centre of the country. The Callao is the main seaport of Peru and one of the most important of South America. Both, the city of Lima and Callao are autonomous and, according to the Law have the same powers. Consequently, any solution to the problem of transportation of Lima is necessarily linked to a solution of the transportation of Callao. Indeed, from a social, economic and cultural perspective the two cities are an unit.

Therefore, it is very important to develop a Transport Master Plan in the metropolitan area of Lima - Callao. The Master Plan developed by Yachiyo Engineering Co. Ltd. define specific plans for: Roads, Rail, Trunk Bus, and Traffic Management, identifying for each relevant projects of transportation for 2025 and 2010.
\end{abstract}

Key words: Network road, public transportation, natural gas, pollution.

\section{A área Metropolitana do Lima e Callao}

A área metropolitana do Lima - Callao está localizada no centro do Peru, frente ao Oceano Pacifico. Lima é a capital e funciona como centro político e administrativo do país, aqui se encontra a Casa do Governo e o Congresso da Republica. O Callao é o principal porto marítimo do Peru e um dos mais importantes da América do Sul, aqui se localiza o Aeroporto Internacional Jorge Chavez, um dos principais nodos aéreos da Costa do Pacifico Sul. Tanto o Município de Lima como o do Callao tem autonomia e de acordo à Lei têm as mesmas atribuições. Nesse sentido, qualquer solução ao problema de transporte do Lima está necessariamente vinculada a uma solução no transporte do Callao. Na realidade, desde uma ótica social, econômica e cultural as duas cidades constituem uma unidade.

Uma análise das atividades econômicas na região metropolitana permite observar que nessa predomina o setor terciário ou de serviços, entretanto as atividades de manufatura e construção também tem um papel importante. Outra característica do Lima e Callao é a atividade informal, a qual se encontra concentrada no centro e na periferia da área metropolitana, a causa como noutros países emergentes é a pobreza, embora esta aqui seja menor com respeito a outras regiões do país. 
Para efeitos do estudo, a Área Metropolitana do Lima e Callao (ano 2004) foi dividida em cinco (05) áreas geográficas, vide Figura № 1 :

Lima Centro: 16 distritos, população de 2.102 .908 no 2004 (26.1\%)

Lima Norte: 8 distritos, população de 1.873.250 no 2004 (23.3\%)

Lima Sul: 12 distritos, população de 1.468 .823 (18.3\%)

Lima Leste: 07 distritos, população 1.786 .665 (22.2\%)

Callao: 06 distritos, população de 811.610 (10.1\%)

No seguinte quadro mostram-se as características de população e PBI da área metropolitana do Lima e Callao, para os anos 2004 e 2025:

\begin{tabular}{|c|c|c|}
\hline Anos & $\begin{array}{c}\text { População } \\
\text { (milhões) }\end{array}$ & $\begin{array}{c}\text { PBI Área } \\
\text { Metropolitana } \\
\text { (S/. Milhões)* }\end{array}$ \\
\hline 2004 & 8,04 & 60,83 \\
\hline 2025 & 10,99 & 148,05 \\
\hline \multicolumn{3}{|c|}{ *US $\$ .1,0=\mathrm{S} / .3,30$}
\end{tabular}

Observa-se que o crescimento da população no período 2004-2025 será de 3,0 milhões e o crescimento do PBI da área de Lima e Callao de S/. 87,2 milhões (26.0 milhões de dólares americanos). Nas Figuras No 2 e 3 mostram-se a densidade da população nos anos 2004 e 2005 por Zona de Trafego.

No quadro seguinte exibem-se os níveis de motorização (numero de viagens) no ano 2004 e como este seria no ano 2025:

\begin{tabular}{|c|c|c|c|c|}
\hline Anos & $\begin{array}{c}\text { Total } \\
\text { (milhões) }\end{array}$ & $\begin{array}{c}\text { Carro } \\
(\%)\end{array}$ & $\begin{array}{c}\text { Táxi } \\
(\%)\end{array}$ & $\begin{array}{c}\text { Transporte } \\
\text { Público } \\
(\%)\end{array}$ \\
\hline 2004 & 12,1 & 15,3 & 7,4 & 77,3 \\
\hline 2025 & 18,0 & 22,5 & 7,0 & 70,5 \\
\hline
\end{tabular}

Na Figura No 4 exibe-se o uso do solo na região para o ano 2025 e na Figura N$^{\circ} 5$ os centros urbanos existentes no ano 2004 e os futuros para o ano 2025. 


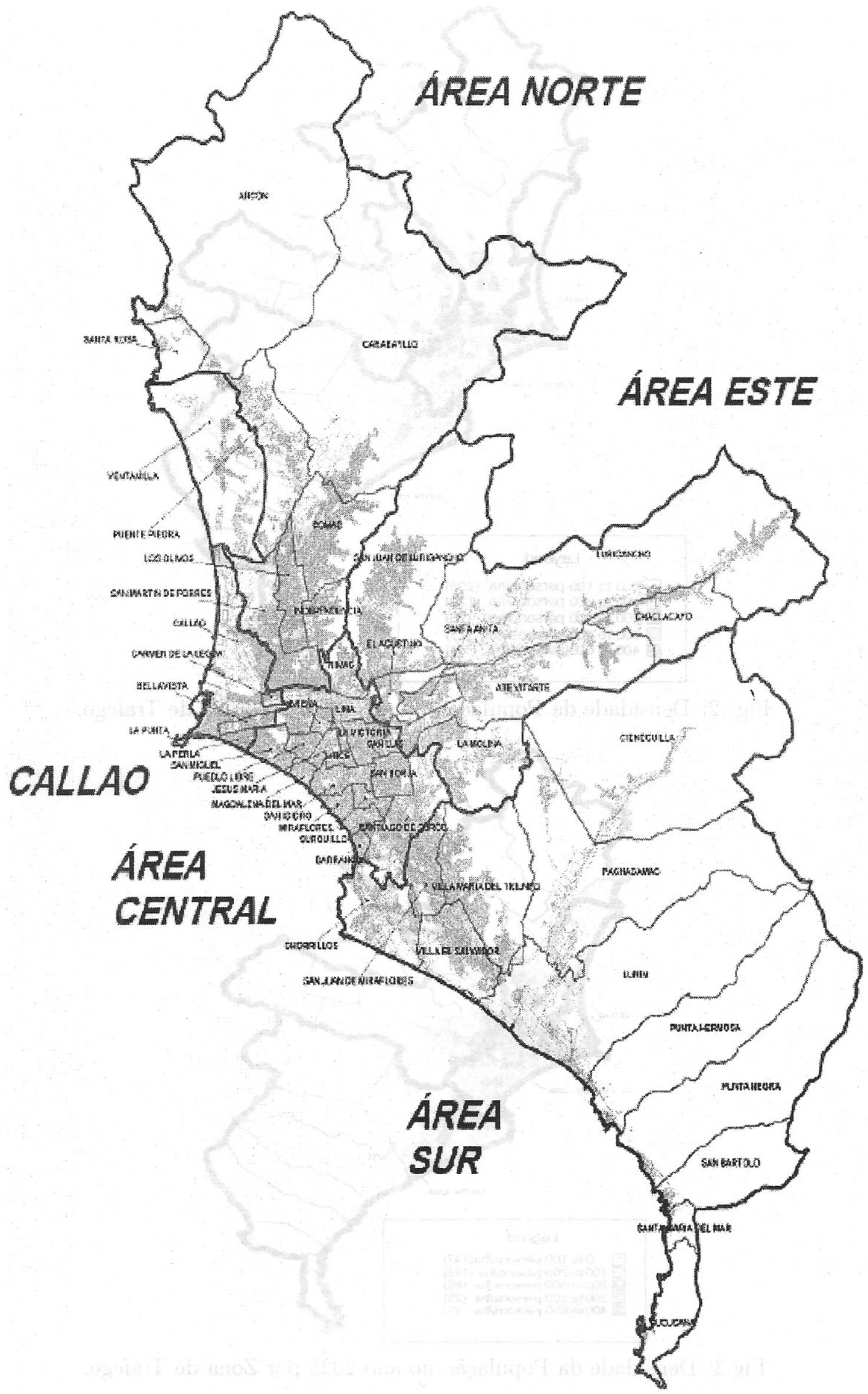

Fig. 1:Área Metropolitana do Lima e Callao. 


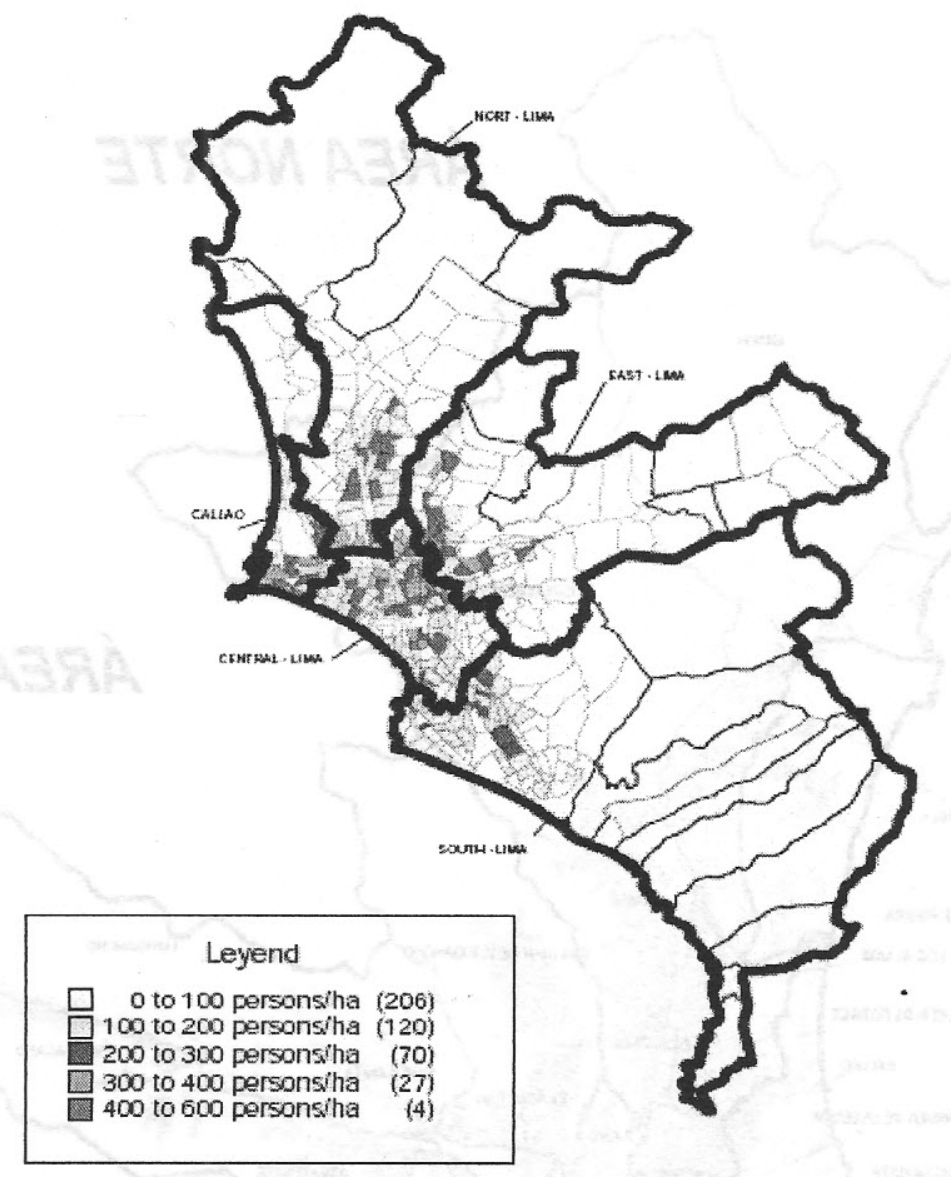

Fig. 2: Densidade da População no ano 2004 por Zona de Trafego.

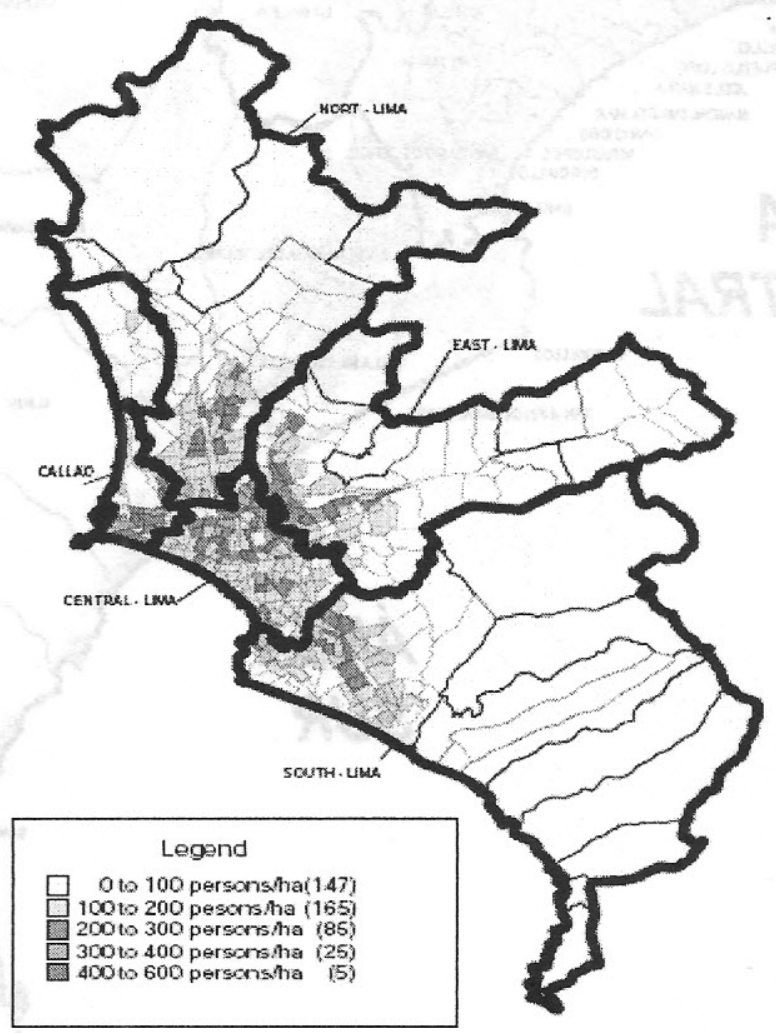

Fig.3: Densidade da População no ano 2025 por Zona de Trafego. 


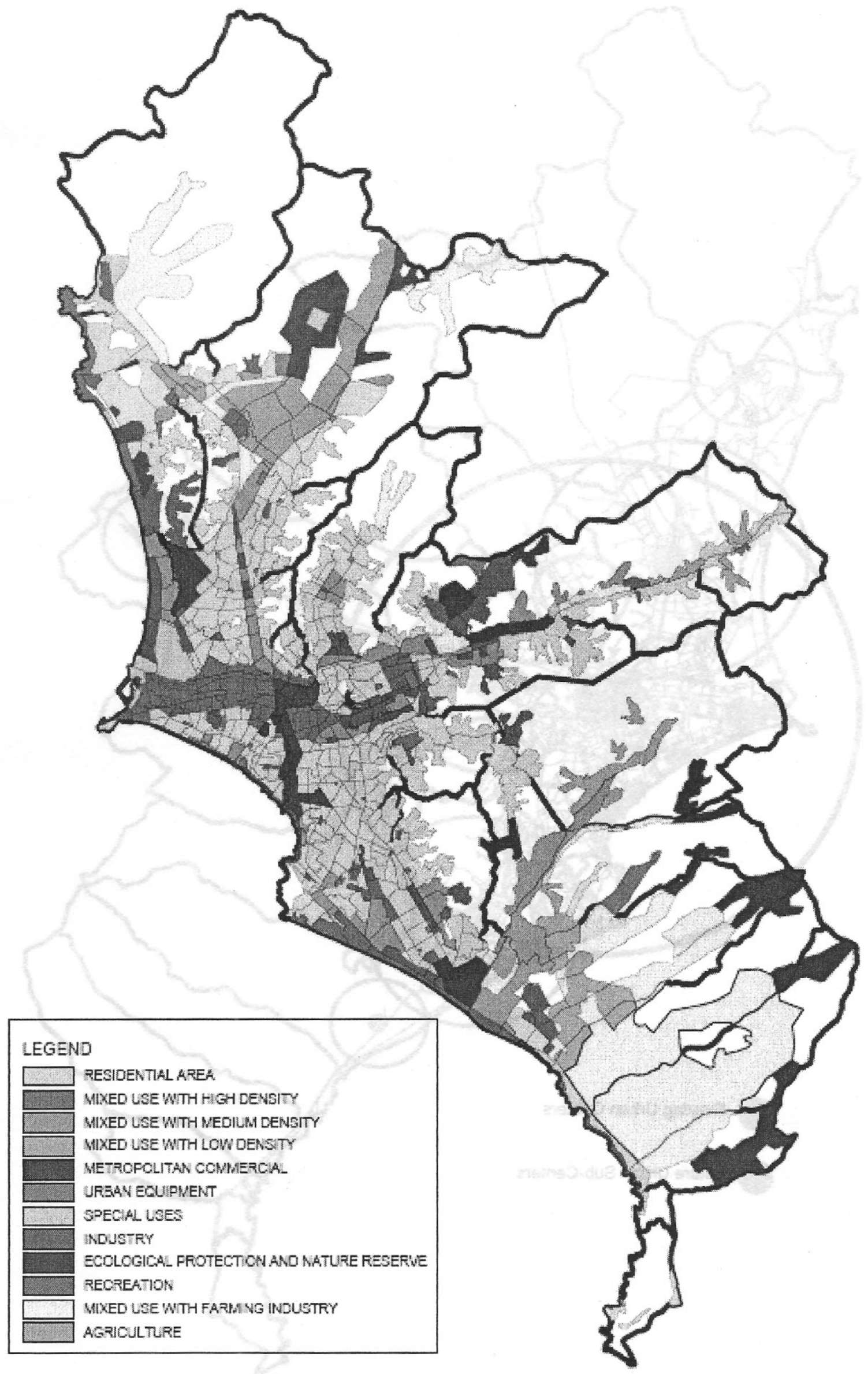

Fig. 4: Uso do Solo no 2025 


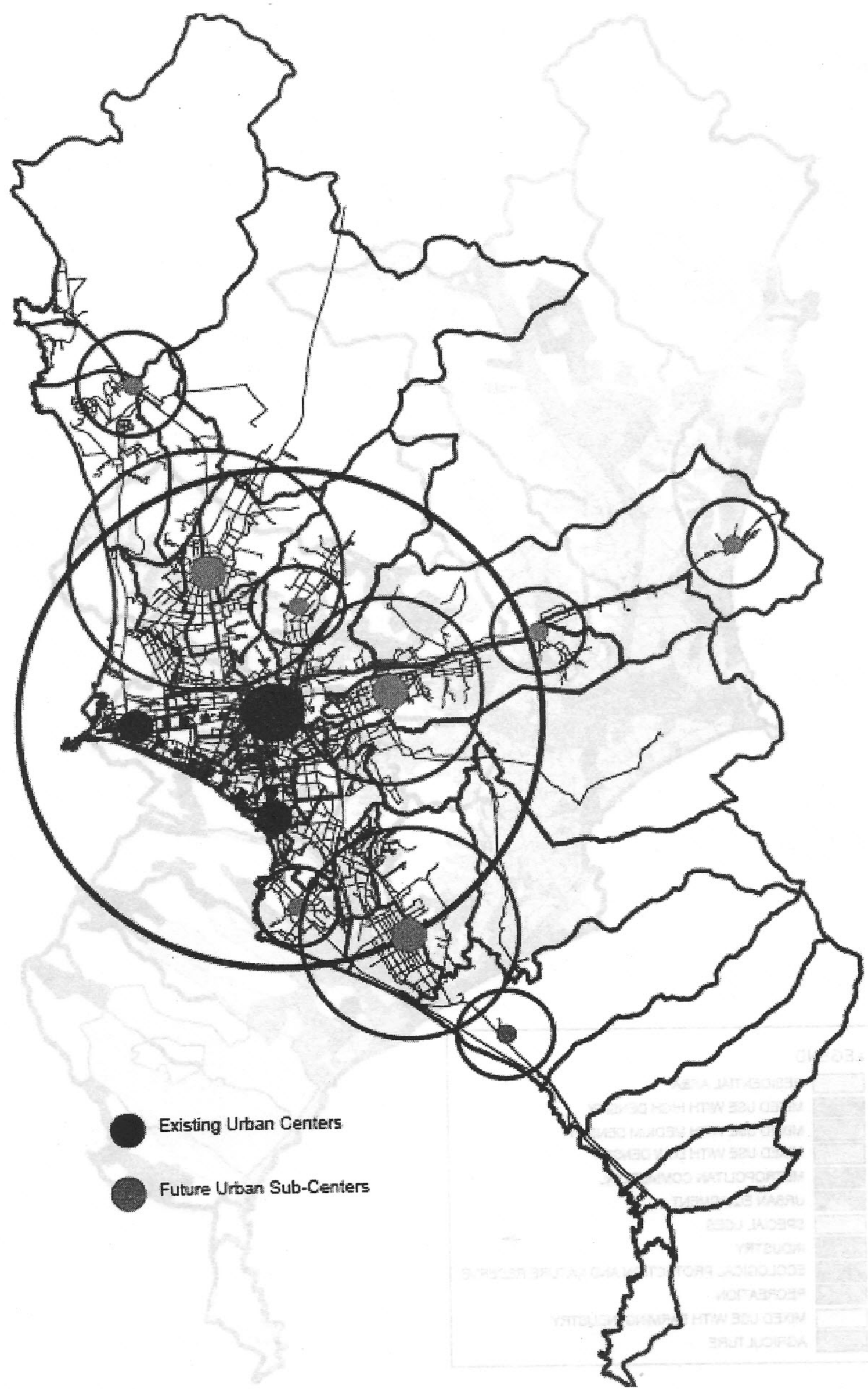

Fig. 5: Centros Urbanos Existentes e Futuros Centros Urbanos Descentralizados 


\section{A Rede Viária Atual}

A atual rede viária básica da área em estudo é mostrada na Figura № 6, nela observase seis (6) eixos radiais e três anéis viários. A futura rede viária troncal também está formulada nesses critérios. Na Figura No 7 mostra-se a localização das vias com alta intensidade em viagens de pessoas o 2004.

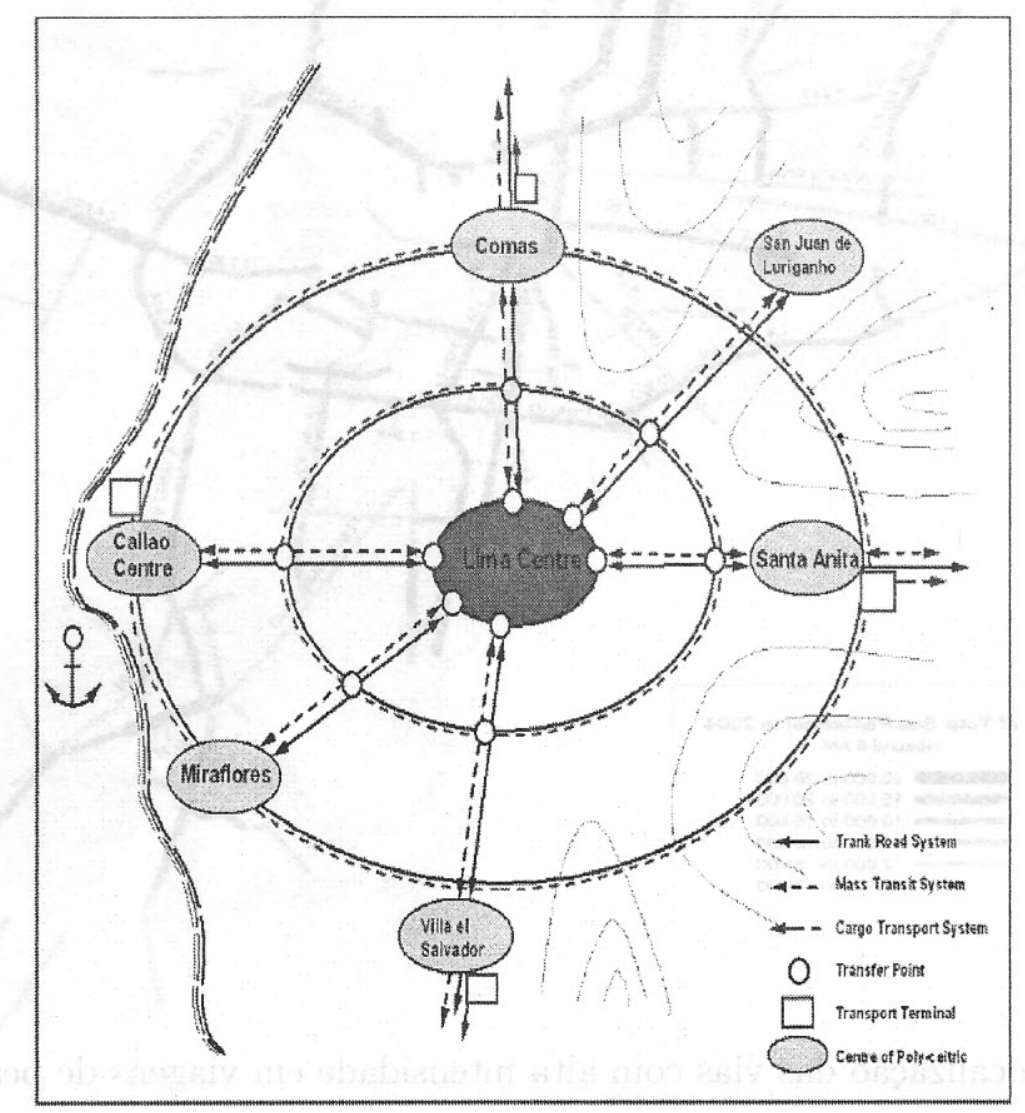

Figura $N^{\circ} 6$ Rede básica do Transporte da área em estudo.

Um dos problemas da área metropolitana do Lima e Callao é que tanto os ônibus interurbanos como os veículos de carga atravessam a área urbana. Uma forma de tratar esse problema é reforçar as vias de desvio para o trafego de carga como se mostra na Figura $N^{0} 8$, assim se diminuirá os acidentes de transito e melhorará as condições do meio ambiente. Com respeito aos ônibus interurbanos, pretende-se criar terminais de ônibus nos limites da área urbana.

Desde o ponto de vista de rotas urbanas na área em estudo, estas chegaram a 574 rotas no 2004. A distancia media das rotas de ônibus foi de aproximadamente $64 \mathrm{~km}$. numa viagem de ida e volta. A percentagem de rotas que excedem $80 \mathrm{~km}$. com relação ao número total é de 24\%, sendo a distancia máxima de uma rota 163 km. Em Bogotá, 


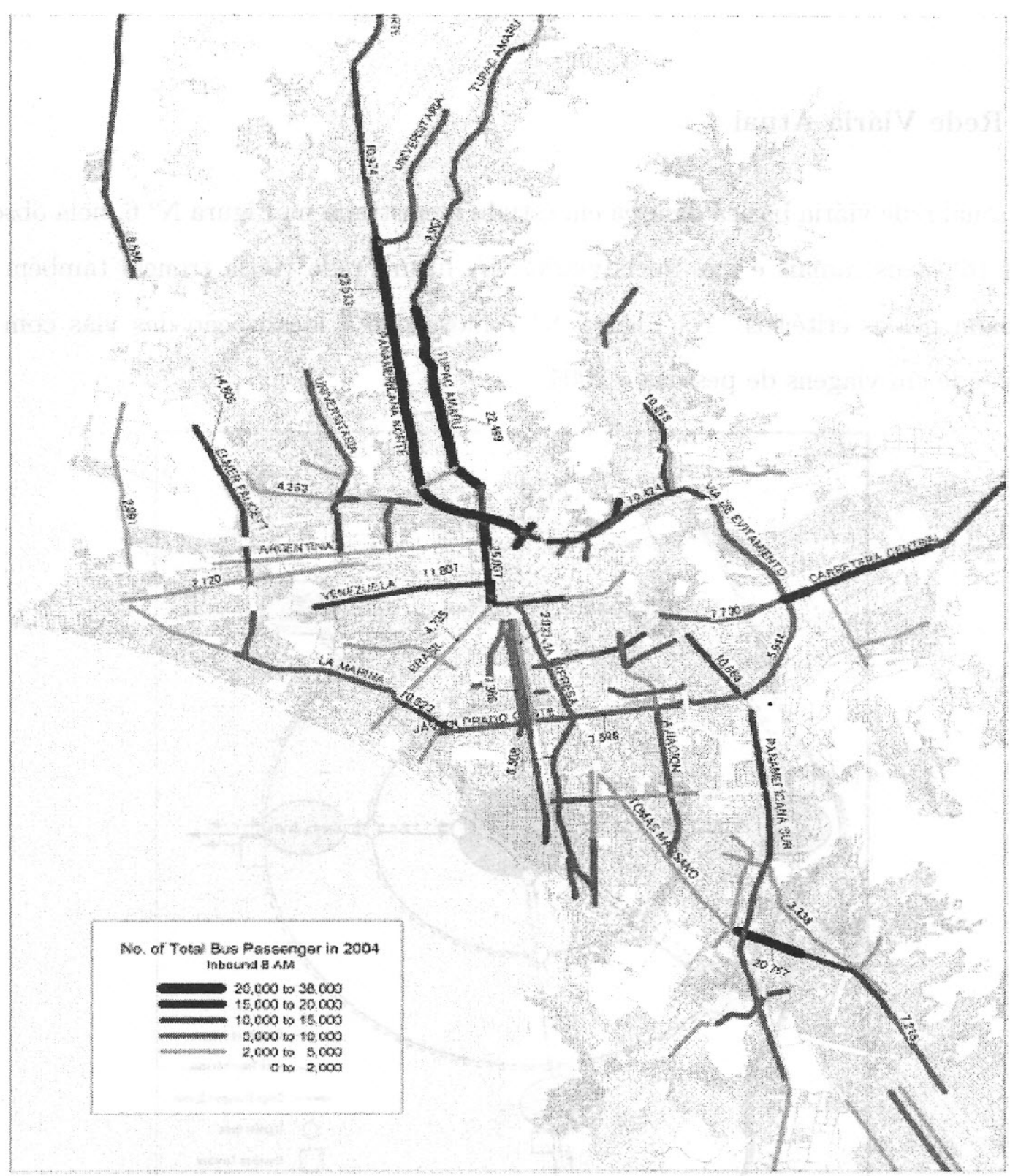

Figura $N^{\circ} 7$ Localização das vias com alta intensidade em viagens de pessoas - 2004 .

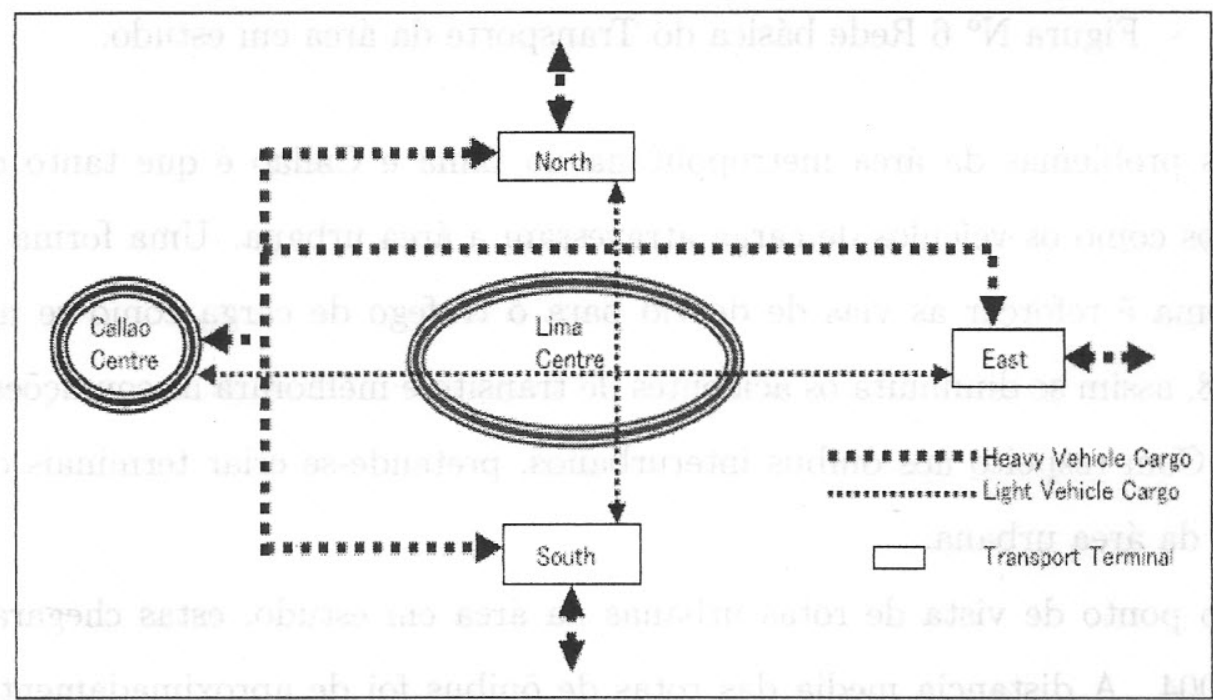

Figura No 8 Diagrama Conceitual: Rotas de Desvio de Carga. 
Colômbia, a media de uma rota é de $50 \mathrm{~km}$. Salienta-se que os especialistas afirmam que rotas com distancias curtas tem uma melhor eficiência operativa. Na Figura $N^{\circ} 9$ mostra-se o ciclo de causa e efeito em relação com os problemas de transporte público na área sob estudo.

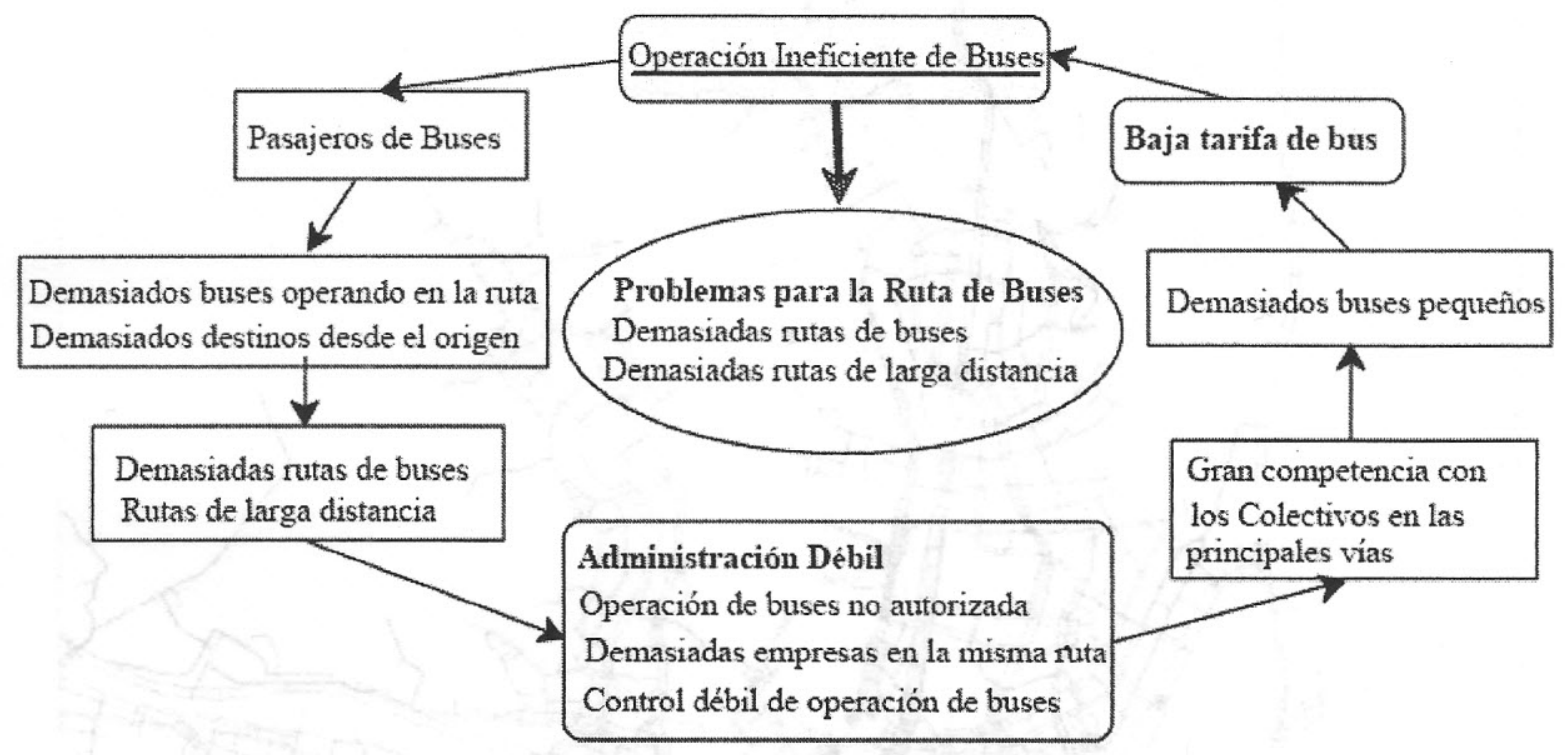

Figura No 9 Problemas das Rotas de Ônibus.

\section{O que acontecerá sem um Plano Mestre de Transportes?}

No ano 2004 a relação Volume/Capacidade $(V / C)>1,5$ atingiu uma parte pequena da rede viária na região metropolitana do Lima e Callao, vide Figura $N^{\circ} 10$. De acordo a estudos realizados estima-se que se nada for feito na área até o ano 2025, a relação Volume/Capacidade $>1,5$ poderia chegar entre $32 \%$ e $50 \%$ de toda a rede viária. Com respeito ao centro da área metropolitana ressalta-se, que em alguns pontos, o ano 2004 o índice de congestão (V/C) já atingiu o 1,5 e estima-se que devido ao crescimento econômico e à motorização da região para o ano 2025 a área de congestão do centro com $V / C>1,5$ poderia chegar ao $100 \%$. Vide Figura No 10 e 11.

Prevê-se também que um maior nível de congestão trairá um conjunto de impactos negativos, tais como:

- Menor velocidade de trafego;

- Maior tempo médio da viagem;

- Aumento na contaminação do meio ambiente $\left(C \mathrm{C}^{2}\right)$;

- Piores níveis de serviço no transporte público. 


\begin{tabular}{|c|c|c|}
\hline Anos & $\begin{array}{c}\text { Velocidade Media } \\
\text { da Viajem } \\
(\mathrm{Km} / \mathrm{h})\end{array}$ & $\begin{array}{c}\text { Tempo Media da } \\
\text { Viagem } \\
\text { (minutos) }\end{array}$ \\
\hline 2004 & 16,8 & 44,9 \\
\hline 2025 & 7,5 & 64,8 \\
\hline
\end{tabular}

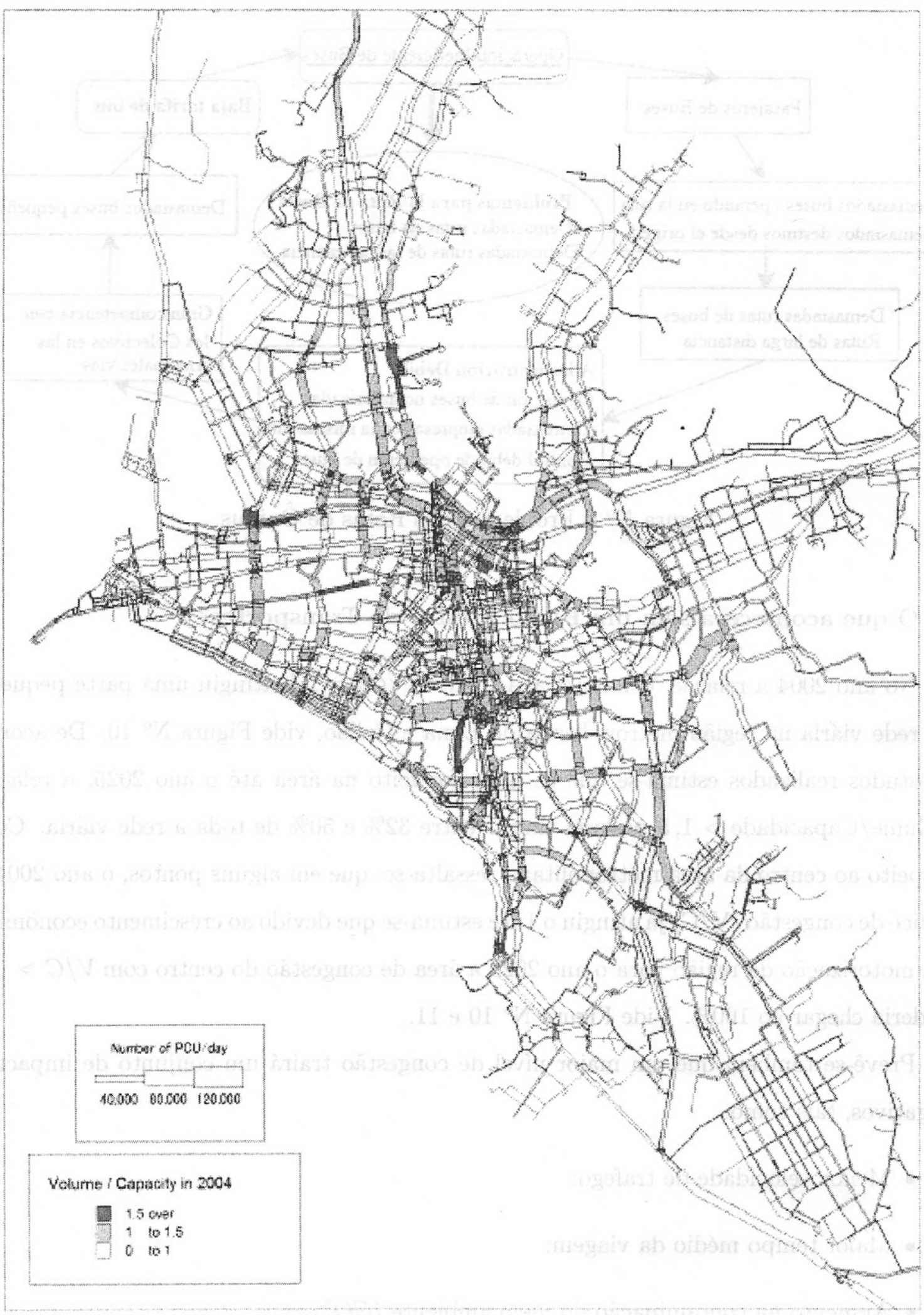

Fig. 10: Trafego nas Redes Viárias e de Transportes - 2004 


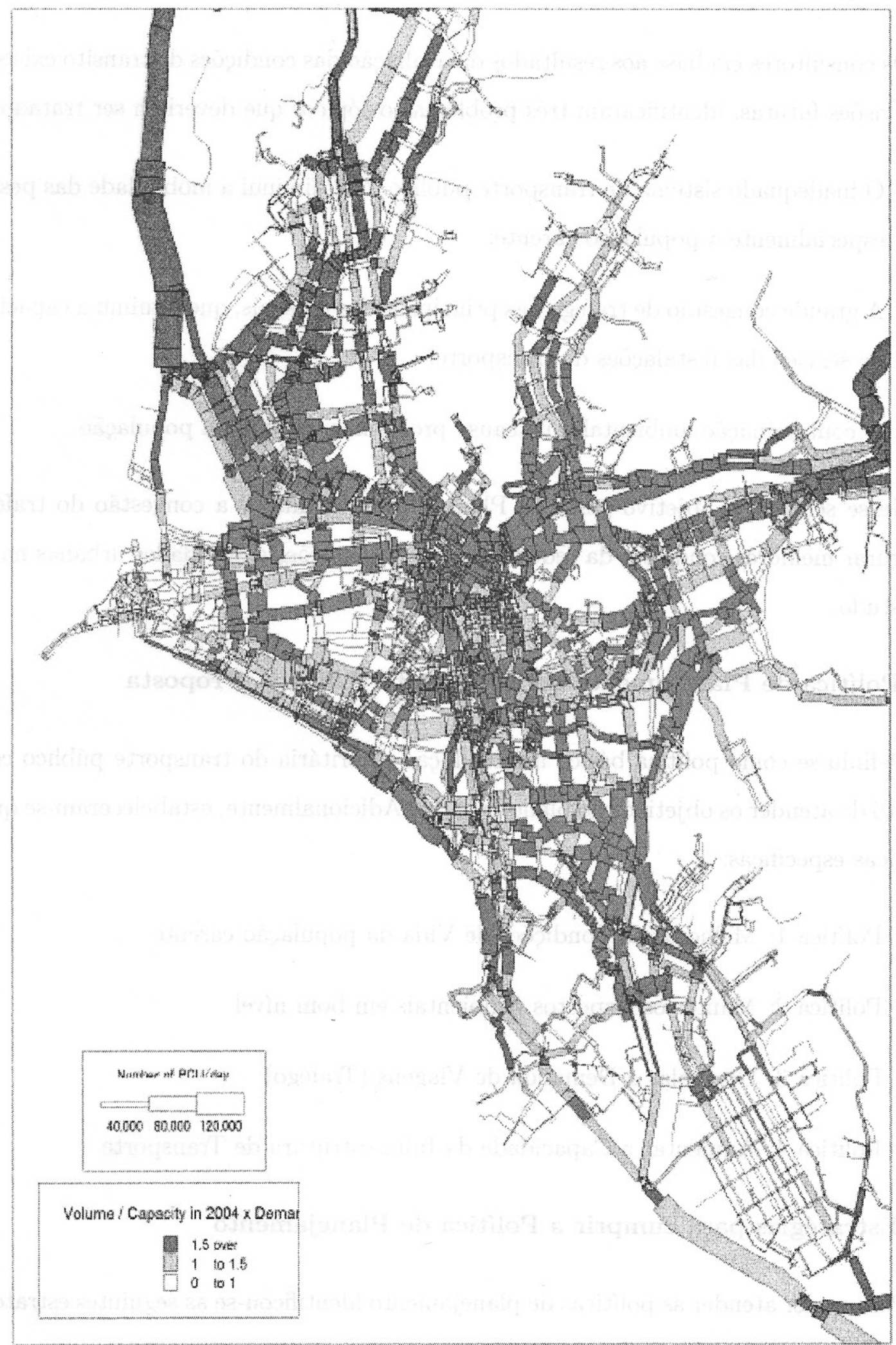

Fig. 11: Demanda Projetada do Trafego nas Redes Viárias e de Transportes para o ano 2025 - Sem Projeto 
4. Política e Estratégia de Plano Mestre

\subsection{Diagnostico Geral - Objetivo}

Os consultores em base aos resultados da avaliação das condições de transito existentes e previsões futuras, identificaram três problemas o tópicos que deveriam ser tratados:

i. O inadequado sistema de transporte público, que diminui a mobilidade das pessoas, especialmente a população carente;

ii. A grande congestão de trafego nas principais vias troncais, que diminui a capacidade de serviço das instalações de transporte;

iii. A contaminação ambiental, que causa problemas à saúde da população.

Nesse sentido, o objetivo geral do Plano Mestre é mitigar a congestão do trafego e assegurar melhores condições da rede viária para as funções e atividades urbanas na área do estudo.

\subsection{Política de Planejamento do Transporte Urbano - Proposta}

Definiu-se como política básica a introdução prioritária do transporte público com o intuito de atender os objetivos do planejamento. Adicionalmente, estabeleceram-se quatro políticas específicas:

- Política 1: Melhorar as Condições de Vida da população carente

- Política 2: Manter os Aspectos Ambientais em bom nível

- Política 3: Controlar a Demanda de Viagens (Trafego)

- Política 4: Aumentar a Capacidade da Infra-estrutura de Transporte

\subsection{Estratégias para cumprir a Política de Planejamento}

Para poder atender as políticas de planejamento identificou-se as seguintes estratégias:

- Estratégias - Política 1: Melhorar as Condições de Vida da população carente

- Assegurar um sistema de transporte público eficiente

- Melhorar a tarifa do transporte público 
- Prover um sistema de transporte público gratuito

- Estratégias - Política 2: Manter os Aspectos Ambientais em bom nível

- Motivar o uso do Gás Natural como energia

- Migrar aos usuários de automóvel ao transporte público

- Garantir a segurança do trânsito e reduzir os acidentes

- Melhorar as frotas das linhas de ônibus

- Estratégias - Política 3: Controlar a Demanda de Viagens (Trafego)

- Introduzir um sistema de transporte público massivo e rápido

- Melhorar o sistema de transporte de ônibus

- Migrar aos usuários de automóvel ao transporte público

- Introduzir o sistema de administração de demanda de tráfego

- Estratégias - Política 4: Aumentar a Capacidade da Infra-estrutura de Transporte

- Reforçar a rede viária

- Melhorar a rede viária da cidade (estender)

- Melhorar o sistema de transporte público

\subsection{Metas ou Objetivos Específicos do Plano Mestre de Transporte Urbano}

Para poder atender as políticas e estratégias mencionadas anteriormente identificaramse as seguintes metas ou objetivos para cada uma das políticas:

- Metas ou Objetivos - Política 1: Melhorar as Condições de Vida da população carente

- Obter um tempo de viagem mais rápido em relação às condições atuais

- Obter uma tarifa de transporte mais barata em relação às condições existentes

- Obter uma redução das distancias que tem que caminhar as pessoas em relação com a condição existente

- Obter um sistema de transporte com maior segurança 
- Metas ou Objetivos - Política 2: Manter os Aspectos Ambientais em bom nível

- Diminuir a poluição do ar em relação com as condições existente

- Construir modernas infra-estruturas de transporte

- Obter um sistema e infra-estrutura de transporte com adequado nível de segurança

- Metas ou Objetivos - Política 3: Controlar a Demanda de Viagens (Tráfego)

- Obter um tempo de viagem mais rápido em relação às condições atuais

- Obter uma tarifa de transporte mais barata em relação às condições existentes

- Obter uma redução nas distancias que tem que caminhar as pessoas em relação com a condição existente

- Implementar um sistema de transporte econômico e com maior conforte

- Obter um sistema de transporte com maior segurança

- Metas ou Objetivos - Política 4: Aumentar a Capacidade da Infra-estrutura de Transporte

- Mitigar a congestão do trafego em relação com as condições existentes

- Obter fluxos de trafego mais contínuos em relação às condições existentes

\subsection{Planos de Transporte Setoriais}

Para poder atender o objetivo geral, políticas, estratégias e metas definiram-se quatro planos setoriais:

- Plano de Desenvolvimento da Infra-estrutura da Rede Viária

- Plano de Desenvolvimento de Transporte Ferroviário

- Plano de Desenvolvimento de Transporte de Ônibus Troncais

- Plano de Gestão do Transporte (Trânsito)

Esses quatro planos setoriais se combinaram para a formulação do Plano Mestre Metropolitano de Transporte de Lima e Callao. 
4.6 Critérios para determinar a Rede de Transporte Futura - Ano 2025

Os critérios utilizados para determinar a rede de transporte futura sobre a qual desenvolver o Plano Mestre, foram:

- Linha de Desejo de Viagem-Pessoa: Eixos radiais e anel viário urbano

- Demanda de Transporte: Introdução de um sistema de transporte massivo nos eixos radiais e anel viário

- Número de Rotas de Ônibus em Operação: Introdução de um sistema de transporte massivo nos eixos radiais e anel viário

- Crescimento da População: Introdução de um sistema de transporte massivo nos eixos radiais leste-oeste e norte-sul

- Áreas Institucionais de Grande Porte: Porto•e Aeroporto Internacional, Estádios Esportivos e Universidades de grande porte, nas vias troncais

- Áreas de Desenvolvimento Comercial de Grande Porte: Norte ( $10 \mathrm{~km}$. de cumprimento), Leste (10 km.) e Sul (15 km.)

- Condições Viárias Existentes: Identificação da rede viária existente com largo maior a $40 \mathrm{Mt}$., onde poderia passar o sistema de transporte rápido.

\subsection{Cenários do Transporte: Ano 2025}

Baseado nas condições do transporte existente, no crescimento da área em estudo e na política de desenvolvimento do transporte público, criou-se três cenários genéricos:

- Sistema Prioritário do Transporte Ferroviário, Figura No 12

- Sistema Prioritário de Ônibus Troncais, Figura No 13

- Sistema de Transporte Combinado (Ferroviário e Ônibus Troncais) 


\section{Railway Transport Network}

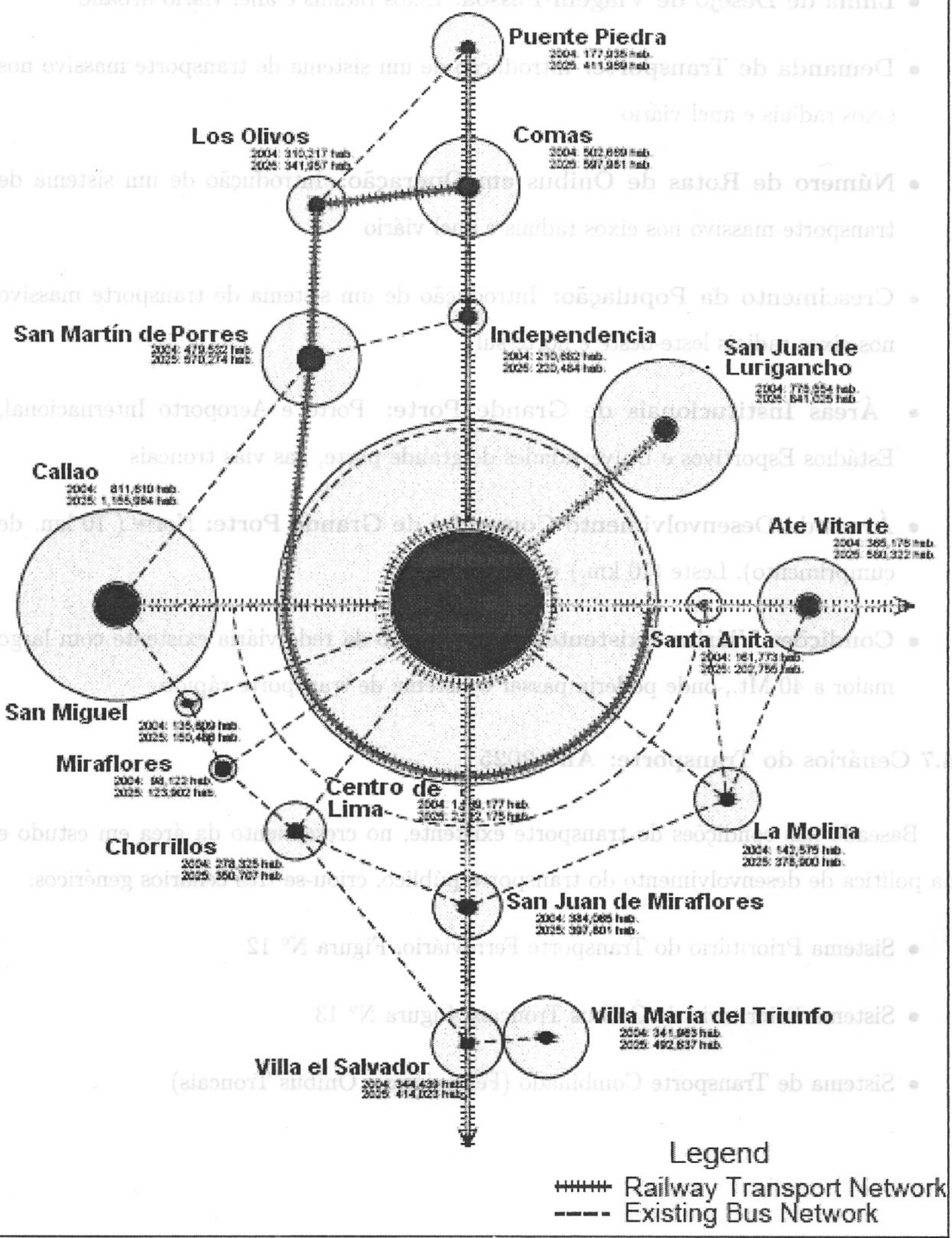

Fig. 12: Transporte Ferroviário 


\section{Trunk Bus Transport Network}

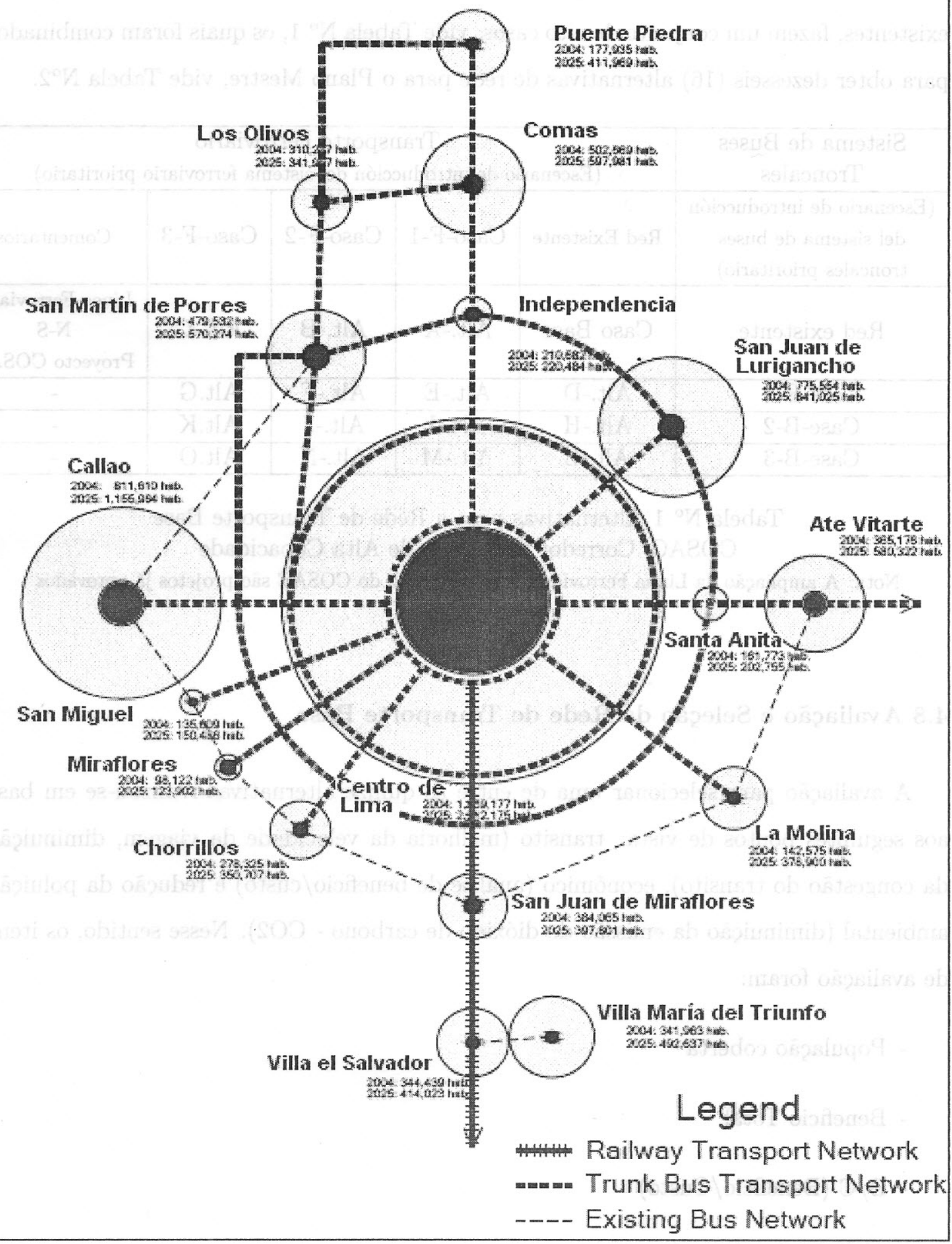

Fig. 13: Prioridade: Ônibus Troncais 
O Sistema de Transporte Ferroviário, vide Figura $N^{\circ}$ 12, tem três opções, Caso F-1: Cor Amarela, Caso F-2: Cor amarela + Cor verde e Caso F-3: Cor amarela + Cor Verde + Cor laranja. O Sistema de Ônibus Troncais, vide Figura No 13, tem também três opções: Caso B-1: Cor amarela, Caso B-2: Cor amarela + Cor verde e caso B-3: Cor amarela + Cor verde + Cor laranja; esses mais o caso da rede ferroviária e a rede viária existentes, fazem um conjunto de oito casos, vide Tabela $N^{\circ} 1$, os quais foram combinados para obter dezesseis (16) alternativas de rede para o Plano Mestre, vide Tabela $N^{\circ} 2$.

\begin{tabular}{|c|c|c|c|c|c|}
\hline $\begin{array}{c}\text { Sistema de Buses } \\
\text { Troncales }\end{array}$ & \multicolumn{5}{|c|}{ Transporte Ferroviario } \\
\hline $\begin{array}{c}\text { (Escenario de introducción } \\
\text { del sistema de buses } \\
\text { troncales prioritario) }\end{array}$ & Red Existente & Caso-F-1 & Caso-F-2 & Caso-F-3 & Comentarios \\
\hline Red existente & Caso Base & Alt.-A & Alt.-B & Alt.-C & $\begin{array}{c}\text { Línea Ferroviaria } \\
\text { N-S } \\
\text { Proyecto COSAC }\end{array}$ \\
\hline Case-B-1 & Alt.-D & Alt.-E & Alt.-F & Alt.G & - \\
\hline Case-B-2 & Alt.-H & Alt.-I & Alt.-J & Alt.K & - \\
\hline Case-B-3 & Alt.-L & Alt.-M & Alt.-N & Alt.O & - \\
\hline
\end{tabular}

Tabela $\mathrm{N}^{\circ} 1$ Alternativas para a Rede de Transporte Base COSAC: Corredor Segregado de Alta Capacidade

Nota: A ampliação da Linha Ferroviária e a construção do COSAC são projetos já aprovados

\subsection{Avaliação e Seleção da Rede de Transporte Base}

A avaliação para selecionar uma de entre as quinze alternativas realizou-se em base aos seguintes pontos de vista: transito (melhoria da velocidade da viagem, diminuição da congestão do transito), econômico (analise de beneficio/custo) e redução da poluição ambiental (diminuição da emissão do dióxido de carbono - CO2). Nesse sentido, os itens de avaliação foram:

- População coberta

- Beneficio Total

- B/C (Beneficio/Custo)

- VAN (Valor Atual Neto)

- Velocidade da Viagem na via 


\begin{tabular}{|c|c|c|c|}
\hline \multirow{2}{*}{$\begin{array}{c}\text { Nombre } \\
\text { de la } \\
\text { Alternativa }\end{array}$} & $\begin{array}{c}\text { Proyectos } \\
\text { Viales }\end{array}$ & $\begin{array}{c}\text { Proyectos de Buses } \\
\text { Troncales }\end{array}$ & $\begin{array}{c}\text { Proyectos } \\
\text { Ferroviarios }\end{array}$ \\
\hline Caso Base & 0 & 0 & 0 \\
\hline Alternativa-A & 33 Proyectos & 0 & 2 Proyectos \\
\hline Alternativa-B & 33 Proyectos & 0 & 4 Proyectos \\
\hline Alternativa-C & 33 Proyectos & 0 & 5 Proyectos \\
\hline Alternativa-D & 33 Proyectos & 6 Proyectos & 0 \\
\hline Alternativa-E & 33 Proyectos & 6 Proyectos & 2 Proyectos \\
\hline Alternativa-F & 33 Proyectos & 6 Proyectos & 4 Proyectos \\
\hline Alternativa-G & 33 Proyectos & 5 Proyectos & 5 Proyectos \\
\hline Alternativa-H & 33 Proyectos & 12 Proyectos & 0 \\
\hline Alternativa-I & 33 Proyectos & 11 Proyectos & 2 Proyectos \\
\hline Alternativa-J & 33 Proyectos & 8 Proyectos & 4 Proyectos \\
\hline Alternativa-K & 33 Proyectos & 7 Proyectos & 5 Proyectos \\
\hline Alternativa-L & 33 Proyectos & 17 Proyectos & 0 \\
\hline Alternativa-M & 33 Proyectos & 16 Proyectos & 2 Proyectos \\
\hline Alternativa-N & 33 Proyectos & 14 Proyectos & 4 Proyectos \\
\hline Alternativa-O & 33 Proyectos & 11 Proyectos & 5 Proyectos \\
\hline
\end{tabular}

Tabela No 2 Listagem de Planos Alternativos e Projetos

- Cumprimento da Congestão

- Redução do CO2

Na Tabela No 3 mostra-se a matriz de avaliação e pontuação de cada uma das alternativas. A opção selecionada foi a Alternativa-N. Na Figura $N^{\circ} 14$ exibe-se o processo de avaliação geral das alternativas e na Figura $N^{\circ} 15$ o processo de execução dos investimentos do Plano Mestre.

\section{O Plano Mestre de Transportes para Lima e Callao}

Selecionada a alternativa de rede para o Plano Mestre, o seguinte passo foi desenvolver planos específicos nos seguintes quatro setores: Rede Viária, Ferrovias, Ônibus Troncais, e Gestão do Trânsito, identificando-se para cada um deles projetos relevantes para o transporte urbano na área metropolitana do Lima e Callao para o horizonte 2025 e 2010.

\subsection{O Plano Mestre: Ano 2025}

\section{a) Infra-estrutura Viária}

A formulação do Plano Mestre para o ano 2025 baseada na demanda de transporte para esse ano, determinou que devessem ser implementados um conjunto de 33 


\begin{tabular}{|c|c|c|c|c|c|c|c|c|c|}
\hline & $\begin{array}{l}\text { 1) Covered } \\
\text { Population }\end{array}$ & $\begin{array}{c}\text { 2) Total } \\
\text { Benefit } \\
\text { (VOC+TTC) }\end{array}$ & 3) $B / C$ & 4) NPV & 5) Speed & $\begin{array}{l}\text { 6) Ratio of } \\
\text { Distance with a } \\
\text { volume-capacity } \\
\text { ratio of over } 1.0\end{array}$ & $\begin{array}{c}\text { 7) Reduction } \\
\text { of } \\
\mathrm{CO} 2 \\
\text { (Ton/day) }\end{array}$ & $\begin{array}{l}\text { Total } \\
\text { 1) } \\
\text { to } \\
7)\end{array}$ & Rank \\
\hline Alternativa-A & 1 & 3 & 2 & 3 & 2 & 3 & 2 & 16 & 14 \\
\hline Alternativa-B & 3 & 6 & 5 & 5 & 5 & 5 & 4 & 33 & 12 \\
\hline Alternativa-C & 6 & 8 & 8 & 8 & 8 & 7 & 6 & 51 & 10 \\
\hline Alternativa-D & 2 & 1 & 1 & 1 & 1 & 1 & 1 & 8 & 15 \\
\hline Alternativa- $\mathrm{E}$ & 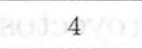 & 4 & 10 & 4 & 3 & 4 & 5 & 34 & 11 \\
\hline Alternativa-F & 10 & 7 & 9 & 7 & 6 & 9 & 8 & 56 & 8 \\
\hline Alternativa-G & 9 & 11 & 4 & 10 & 10 & 10 & 10 & 64 & 7 \\
\hline Alternativa- $\mathrm{H}$ & 5 & 2 & 7 & 2 & 4 & 11 & 3 & 25 & 13 \\
\hline Alternativa-I & 8 & 9 & 13 & 13 & 11 & 8 & 11 & 73 & 5 \\
\hline Alternativa-J & 11 & 10 & 11 & 12 & 12 & 12 & 9 & 77 & 4 \\
\hline Alternativa- $K$ & 12 & 12 & 3 & 9 & 9 & 11 & 12 & 68 & 6 \\
\hline Alternativa- $\mathrm{L}$ & 7 & 5 & 15 & 6 & 7 & 6 & 7 & 53 & 9 \\
\hline Alternativa-M & 13 & 13 & 14 & 15 & 14 & 14 & 15 & 98 & 2 \\
\hline Alternativa-N & 14 & 15 & 12 & 14 & 15 & 15 & 7) 14 & 99 & 1 \\
\hline Alternativa-O & 15 & 14 & 6 & 11 & 13 & 13 & 13 & 85 & 3 \\
\hline
\end{tabular}

Tabela No 3 Matriz de Avaliação e Pontuação por Cenários Alternativos

projetos tanto em construção, melhoramento, expansão como de reabilitação viária, avaliados em 2.374 milhões de dólares americanos.

\section{b) Ferrovias}

Serão construídas quatro linhas para conectar a área suburbana ao centro da cidade, isto envolve a execução de sete projetos avaliados em 2.024 milhões de dólares americanos.

\section{c) Ônibus Troncais}

Com o intuito de se formar um "Sistema de Onibus Troncais e Alimentadores"se construirão vias, faixas e terminais de ônibus, fazendo um total de 18 projetos avaliados em 981.0 milhões de dólares americanos.

\section{d) Gestão do Trânsito}

Para a utilização das instalações viárias existentes e para melhorar as suas capacidades atuais, será necessário aprimorar o sistema de controle de trânsito, semaforização e, sinalização horizontal e vertical. Adicionalmente, se introduzirão sistemas de gestão de demanda de trafego. Em conjunto serão 10 projetos avaliados em 156.0 milhões de dólares americanos. 


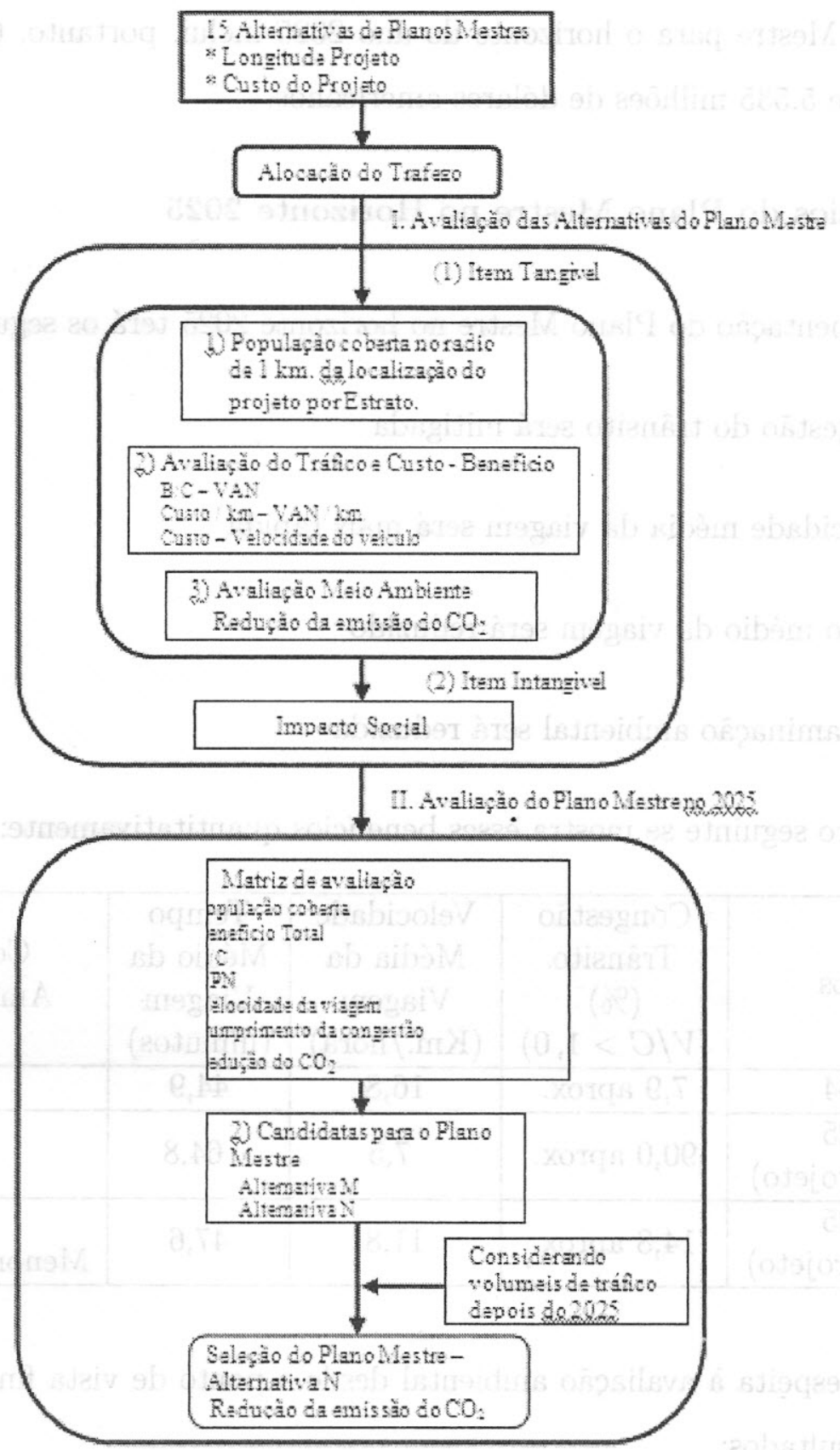

Fig. 14: Processo Geral de Avaliação das Alternativas

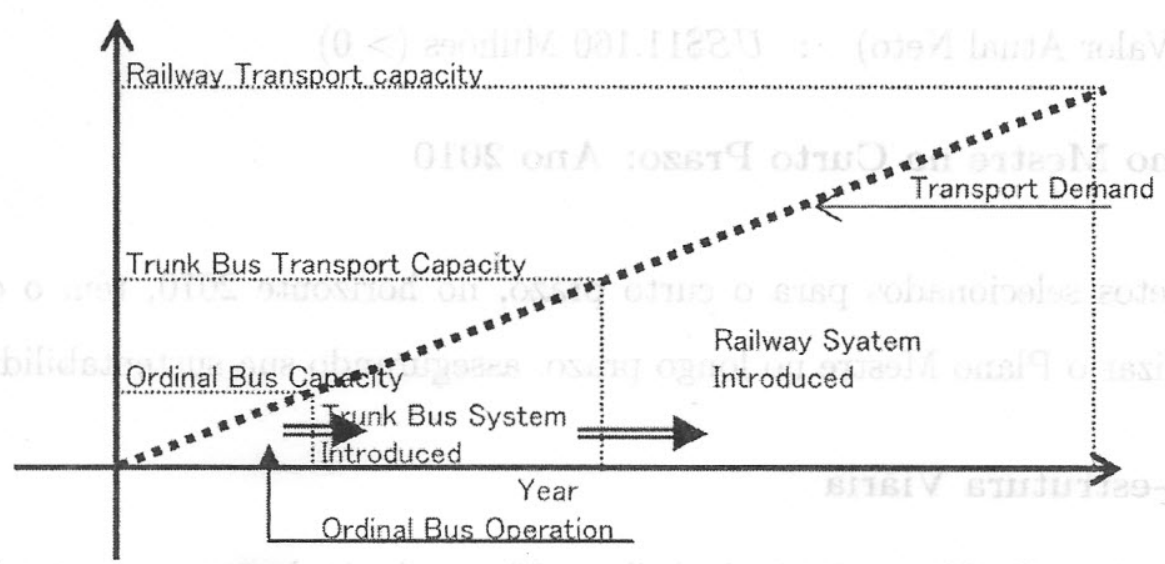

Fig. 15: Processo de Execução dos Investimentos do Plano Mestre 
O Plano Mestre para o horizonte do ano 2025 inclui, portanto, 68 projetos com um orçamento de 5.535 milhões de dólares americanos.

\subsection{Benefícios do Plano Mestre no Horizonte 2025}

A implementação do Plano Mestre no horizonte 2025 terá os seguintes benefícios:

- A congestão do trânsito será mitigada

- A velocidade média da viagem será mais rápida

- O tmpo médio da viagem será reduzido

- A contaminação ambiental será reduzida

No quadro seguinte se mostra esses benefícios quantitativamente:

\begin{tabular}{|c|c|c|c|c|}
\hline Anos & $\begin{array}{c}\text { Congestão } \\
\text { Trânsito } \\
(\%) \\
(V / C>1,0)\end{array}$ & $\begin{array}{c}\text { Velocidade } \\
\text { Média da } \\
\text { Viagem } \\
(\text { Km./hora })\end{array}$ & $\begin{array}{c}\text { Tempo } \\
\text { Médio da } \\
\text { Viagem } \\
(\text { minutos })\end{array}$ & $\begin{array}{c}\text { Contaminação } \\
\text { Ambiental - CO2 }\end{array}$ \\
\hline 2004 & 7,9 aprox. & 16,8 & 44,9 & 8000 \\
\hline $\begin{array}{c}2025 \\
\text { (Sem Projeto) }\end{array}$ & 90,0 aprox. & 7,5 & 64,8 & 38000 \\
\hline $\begin{array}{c}2025 \\
(\text { Com Projeto) }\end{array}$ & 14,8 aprox. & 11,8 & 47,6 & $\begin{array}{c}16000 \\
\text { Menor em 57\% aprox. }\end{array}$ \\
\hline
\end{tabular}

No que respeita à avaliação ambiental desde o ponto de vista financeiro obteve-se os seguintes resultados:

Relação Beneficio/Custo : 4,95 (> 1,0)

VAN (Valor Atual Neto) : US\$11.160 Milhões $(>0)$

\subsection{O Plano Mestre no Curto Prazo: Ano 2010}

Os projetos selecionados para o curto prazo, no horizonte 2010, têm o objetivo de operacionalizar o Plano Mestre no longo prazo, assegurando sua sustentabilidade.

\section{a) Infra-estrutura Viária}

Construir-se-ão 03 terminais de ônibus, 03 terminais de trens, um trecho na zona sul (Villa El Salvador), um trecho no leste (San Juan de Lurigancho) e se melhorará um trecho na zona norte (Comas). 


\section{b) Ferrovias}

A demanda de trânsito, no ano 2010, do Centro da cidade a San Juan de Lurigancho e do Centro a Villa El Salvador excederá a capacidade dos ônibus troncais. Portanto, o trem atual (Villa El Salvador-Atocongo) será estendido para reduzir a congestão do trânsito e melhorar o nível de serviço. Assim, se construirão:

- 01 ramal do trem de 11,7 Km. Atocongo-Hospital 2 de Mayo;

- 01 ramal do trem de 13,0 Km. Hospital 2 de Mayo-San Juan de Lurigancho.

\section{c) Ônibus Troncais}

Se implementará o "Sistema Tronco-Alimentador de Ônibus", o objetivo é que o serviço de ônibus troncais opere a maior velocidade de operação que o serviço de ônibus convencionais (alimentadores), estes deverão operar nas áreas vizinhas aos terminais de ônibus troncais, o propósito é que transporte aos passageiros desde e para o terminal. O serviço de ônibus alimentadores operará nas rotas atuais, no entanto, algumas serão eliminadas e outras integradas.

\section{d) Gestão do Trânsito}

Para mitigar a congestão do trânsito se realizarão investimentos em:

- Sinalização horizontal e vertical; $\quad$ - Monitoreo de acidentes;

- Semáforização;

- Gestão da demanda de trafego;

- Melhoramento de interseções;

- Controle de estacionamentos.

- Inspeção de veículos (carros, ônibus, etc.);

\subsection{Avaliação do Plano Mestre no Curto Prazo (2010)}

Os principais benefícios do Plano Mestre no Curto Prazo é a diminuição do tempo da viagem e o incremento de velocidade, vide o seguinte quadro:

\begin{tabular}{|c|c|c|}
\hline Anos & $\begin{array}{c}\text { Velocidade Media } \\
\text { da Viajem } \\
(\mathrm{Km} / \mathrm{h})\end{array}$ & $\begin{array}{c}\text { Tempo Media da } \\
\text { Viagem } \\
\text { (minutos })\end{array}$ \\
\hline $\begin{array}{c}2010 \\
\text { (Sem o Projeto) }\end{array}$ & 16,8 & 56,0 \\
\hline $\begin{array}{c}2010 \\
\text { (Com o Projeto) }\end{array}$ & 14,0 & 49,0 \\
\hline
\end{tabular}

Uma avaliação econômico-financeira do Plano Mestre no horizonte 2010 da os seguintes resultados: 
- Relação Beneficio/Custo 3,18

- Valor Atual Neto (VAN) US\$. 2.688 Milhões de dólares americanos

- Ingressos (Verba) US\$. 1.028 Milhões de dólares americanos

- Custos (Despensas) US\$ 1.003 Milhões de dólares americanos

\section{Conclusões e Recomendações}

A realização dos projetos integrais recomendados pelo Plano Mestre de Transporte Urbano na área metropolitana de Lima e Callao exige a criação de uma nova organização ou reforçar as existentes que dependem de uma ou outra cidade. As atuais estruturas de organização, responsáveis pelo trânsito e transporte na região metropolitana estão a cargo de várias autoridades individuais, cada autoridade possui suficiente tecnologia de engenharia para os aspectos de transporte, no entanto, é fraca para promover e realizar os projetos de transporte porque estes envolvem a participação de mais de uma dessas organizações. A execução dos projetos recomendados no Plano Mestre exige, portanto:

- Que a nova organização segure uma coordenação continua e eficiente com as atuais, ou que as atuais criem adequados níveis de coordenação;

- Que a organização seja forte desde o ponto de vista político e técnico;

- Que a organização forneça tecnologias adequadas.

Infelizmente o Plano Mestre de Transporte Urbano não trata o transporte em bicicletas como parte do Estudo, os consultores argumentaram que nesse momento se estava realizando de maneira específica o Estudo do Plano Mestre para o Transporte em Bicicleta pela FONAM (Fundo Nacional do Meio Ambiente no Peru) e, que esse era o motivo para não incluí-lo. Nesse sentido, a influência do transporte não motorizado, que pode ter um importante impacto na periferia da cidade, não foi analisada no marco do Plano Mestre de Transporte Urbano, o qual houvesse sido desejável.

\section{REFERENCIAS}

Plan Maestro de Transporte Urbano para el Área Metropolitana de Lima y Callao en la República del Perú. (Espanhol). Yachiyo Engineering Co. Ltd., em associação com Pacific Consultants Internacional. Agosto, 2005. 